AECT Affiliates

\author{
By Mary Herring, AECT President
}

have had the privilege of traveling

to many of our affiliated organizations this year to speak for AECT and ISMF and to attend their yearly conferences. The hospitality has been overwhelming, interest in collaboration of our two organizations satisfying, conference's very high quality, and people I have met, outstanding. These trips have been a highlight of this year for me. Representing AECT and ISMF and joining there great professionals has indeed been a privilege and an honor.

As Thomas Freidman reminds us, through the connectivity of technology the world is becoming more flat. Affiliating with like organizations serves to strengthen both organizations through opening opportunities for windows into each other's worlds, collaboration, and discussions that inform us all.

According to our by-laws, affiliates are defined as:

Any active local, state, regional, national or international organization whose interests and purposes are similar to those of the Association for Educational Communications and Technology, and whose constitution and bylaws are consistent with the constitution and bylaws of the Association..., may, upon written request and on approval of the Executive Committee of the Board become affiliated with the Association for Educational
Communications and Technology to work together more effectively in the achievement of their common goals.

We have five categories of affiliation: State, Regional, National, International, and Chapter. Lists of affiliates can be found linked off the AECT home page. Our state affiliates often have close ties to ISMF through their own state run student media festivals. Several of them support student winner's submissions to ISMF. Check out the links on the State Affiliate page at aect.org for more information.

\section{Great news!}

Two new state organizations are in the works, Michigan and Kansas. These chapters are being organized by individuals who are active in AECT. Their activities will align closely with AECT's.

\section{Affiliate Opportunities}

I recently attended the Canadian Network for Innovation in Education conference in Ottawa to explore a joint affiliation. A previously affiliated group (AMTEC) has folded into this new organization. As I prepared for this meeting, I explored what AECT is able to offer affiliates. The list of opportunities included:

- AECT international online membership

- A session track at AECT annual conference

- Access to AECT electronic resources

- Complementary conference registra- tion in each organization for their presidents (or designees)

- Opportunities to publish in proceedings and journals

- Promotion of conferences at AECT conference

In return, the organizations offer similar options to AECT.

\section{Needed: Affiliate Board Member}

AECT has long had an affiliate board member. Over the past year that position has been empty as we have reexamined its role. The increasing growth of member organizations showcases the need to bring these important voices to the board of directors table. Mike Spector and I will be looking for someone to appoint to this position. Interested? Contact one of us. We will host a gathering in Louisville for all affiliate representatives so that they and their representative can get to know one another and so that we can say thank you for all they bring to AECT.

So to Leslie Blatt, Michelle Lenderman, Diane Hughes, Ray Whitley and Christina Rogoza-a big thank you for your support and for the chance to share information about AECT and ISMF with your constituents. It is committed professionals like you who keep us all connected and making a difference in this everflattening world. Hats off to our affiliated organizations for the richness that they bring to their members and to AECT! 